Pak. j. sci. ind. res. Ser. B: biol. sci. 201356 (2) 105-109

\title{
Statistical Modelling of a Facile Process for the Extraction of Crude Constituents of Curcuma longa
}

\author{
Bode Daramola \\ Department of Food Technology Federal Polytechnic, PMB 5351, Ado-Ekiti, \\ Ekiti State, Nigeria \\ (received February 25, 2012; revised November 12, 2012; accepted February 14, 2013)
}

\begin{abstract}
A preliminary study on a process for the extractions of crude constituents of Curcuma longa using statistical modelling is reported. The effects of three independent variables namely; solvent system (ethanol 1:0/water 0:1), temperature ${ }^{\circ} \mathrm{C}(30-70)$ and contact time ( $\left.\min \right)(5-30)$ were studied using the central composite rotatable design on the extraction of the crude constituents of the rhizome. Three characteristics of crude extracts, namely; total phenolic content, colourimetric index and relative total soluble solids as responses were studied. Equations for predicting the responses were developed and adequacy confirmed using analysis of variance and residual assessment. The empirical model could find usefulness as a base data for extraction of the crude constituent of C. longa.
\end{abstract}

Keywords: Curcuma longa, extraction process, phenolic content, dietary colourant, statistical modelling

\section{Introduction}

Ethno medicinal values of Curcuma longa have been recognised since pre-historic times. It is used in ethno medicinal formulations for the treatment of spectrum of diseases notably heart disorder, liver problems, asthma, arthritis, gall bladder infections, digestive disorders and dysmenorrhoea (Adeniji, 2003). The herb is endowed with a colourant of superior tinctorial strength in comparison to synthetic dye of similar shade e.g. tartrazine (Henry, 1996) therefore, prefered to use in colouring delicasies such as soup and puddies. The rhizome is a herb of domestic commerce in western Nigeria and could contribute to import substitution therefore, such goal should be prioritised. Enhancing agronomical value essentially involves exploiting upstream and downstream opportunities that abound in agricultural produce. At the entry point of the opportunity chain lies feed stock, a product of primary process usually characterised with low technology process but less effective. It also reduces packaging and transportation cost in comparison to the large sized rhizomes. Using high technology, such feed stock could be processed to yield speciality natural products in nature of dietary colourant or herbal medicine principally inherent to $C$. longa. Catalogue of bio active principle and prospective pharmacological consequence of $C$. longa have been given by Henry (1996). Added to this,

*Author for correspondence; E-mail: daramola_bode@yahoo.co.uk the active components of $C$. longa have been modified to enhance its antifungal, antibacterial (Misra et al., 2007) and anticancerous properties (Rojsitthisak et al., 2011). Crude extracts which serve as feed stock for colourant and bioactive components inherent in C. longa are of different chemical groups. Therefore, the components could be preliminarily separated using appropriate solvent system enhanced by physical variables such as time and temperature.

The aim of this study was to model a facile process using temperature, contact time and solvent system as independent variables for the extraction of crude constituents of $C$. longa with emphasis on dietary colourant and therapeutic components which could serve as feedstock for the production of specialized natural product with therapeutic (antibiotics) or colourant specificities consequently lending enhancement of agronomical value of C. longa.

\section{Materials and Methods}

Materials. Wholesome Curcuma longa rhizome (red ginger) fingers were obtained from central commercial market in Ado-Ekiti, Nigeria. All chemicals used were of analytical grade: ethanol and distilled water.

Extraction protocol. Curcuma longa rhizome without blemish was washed, peeled and dried. The dried product was milled and used in subsequent crude constituent extraction process. The schematic diagram for the 
selected bioactive constituent recovery process using two solvents mixture system, contact time, medium temperature as extraction independent variables is shown in Fig. 1. Details of extraction variables in the experimental design are presented in Table 1. The lowest and highest levels of independent variables were chosen from the results of preliminary investigations.

Experimental design. A central composite rotatable design for $\mathrm{k}=3$ was used (Cochran and Cox, 1957). The 3-factor, 5-level design generated 20 sample combinations comprising eight points peculiar to $2^{3}$ factorial, six star points and six central points for replication. The effects of independent variables namely: solvent-mixture ratio, temperature and contact time were noted for extraction of the crude constituents. The crude constituents markers namely: total phenolic content, tinctorial (colour intensity) index and relative total soluble solids of solution were evaluated. Step-wise regression analyses were performed on the data to yield equations for predicting extraction of crude constituents of $C$. longa with reference to designated functionality.

Analytical Methods. Relative total soluble solids determination. Refractive index of sample was measured using Abbey Refractometer (ABBE 325, ZUZI) and

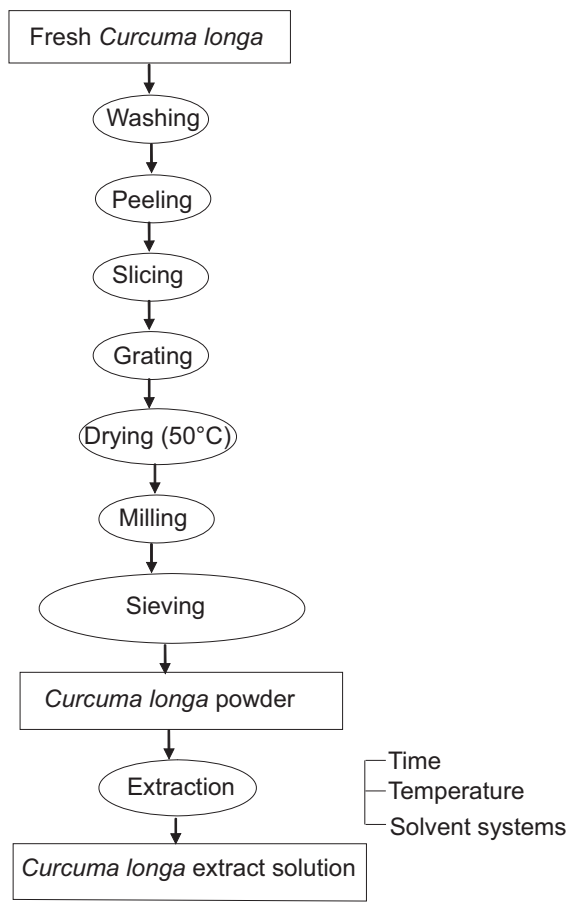

Fig. 1. Flow sheet for the extraction of crude constitutents of $C$. longa. corresponding soluble solids was determined using a procedure adapted from sugar analysis method and reference to appropriate designated table. Result is reported as relative total soluble solids (Table 2).

Determination of colour density/polymeric colour. Colour density was determined according to the method described by Wrolstrad et al. (1982). Colour density was calculated as the sum of the absorbances at $420 \mathrm{~nm}$ and $510 \mathrm{~nm}$.

Evaluation of total phenolic content. Total phenolic content was evaluated according to the method described by Taga et al. (1984). Briefly, a $100 \mu \mathrm{L}$ of Folin - Ciocalteau reagent ( $2 \mathrm{~N}$ wrt acid Fluka Chemic AG - Ch-9470 BUCHS) was added to each sample $(20 \mu \mathrm{L})$ and well mixed after addition of $1.58 \mathrm{~mL}$ of water. After $30 \mathrm{~s}, 300 \mu \mathrm{L}$ of $2 \%$ sodium carbonate solution was added and the sample tubes were left at room temperature for $2 \mathrm{~h}$. The absorbance(A) of the developed blue colour was measured at $750 \mathrm{~nm}$ using Unicam Helios \& uv/vis/spectrophotometer. A plot of $\mathrm{A}_{750} \mathrm{~nm}$ against corresponding concentration was used to calculate phenolic content using ascorbic acid as standard and result expressed in mg ascorbic acid equivalent/g sample.

Statistical analysis. The central composite orthogonal designed was analysed as reported by Cochran and Cox (1957). Each of the X-matrix was multiplied by the Y-column (response) to obtain corresponding sums of products that is $0 \mathrm{y}$ to $13 \mathrm{y}$ for $\mathrm{X}_{\mathrm{O}}$ to $\mathrm{X}_{1} \mathrm{X}_{3}$.Consequently, the coefficients $b_{0}$ to $b_{13}$ were calculate as:

Table 1. Process variables used in the central composite rotatable design $(\mathrm{k}=3)$ levels

\begin{tabular}{lllllll}
\hline \hline Independent variable & Code & -1.682 & -1 & 0 & 1 & 1.682 \\
Time $(\mathrm{min})$ & $\mathrm{X}_{1}$ & 5 & 10 & 15 & 20 & 30 \\
Temp $\left({ }^{\circ} \mathrm{C}\right)$ & $\mathrm{X}_{2}$ & 30 & 40 & 50 & 60 & 70 \\
Solvent(water/ethanol) & $\mathrm{X}_{3}$ & $1: 0$ & $2: 1$ & $1: 1$ & $1: 2$ & $0: 1$ \\
\hline \hline
\end{tabular}

Table 2. Range of values for total phenolic content, tinctorial index and relative total soluble solids

\begin{tabular}{ll}
\hline \hline Model parameter & Range value \\
\hline Total phenolic content mg/g & $0.001-0.051$ \\
Tinctorial index & $0.03-0.45$ \\
Relative total soluble solids (\%) & $4-23-$ \\
\hline \hline
\end{tabular}




$$
\begin{aligned}
& \mathrm{b}_{0}=0.166338(0 \mathrm{y})-0.056791 \Sigma \text { (iiy) } \\
& \text { bi }=0.073224 \text { (iy) } \\
& \text { bii }=0.062500 \text { (iiy) }+0.006889 \Sigma \text { (iiy) } \\
& -0.056791(\mathrm{Oy}) \\
& \mathrm{bij}=0.125000(\mathrm{ijy})
\end{aligned}
$$

The quadratic model was fitted using the regression coefficients and the predicted response calculated for each of the observed values. The model was observed for adequacy by subject to analysis of variance and residual analysis.

\section{Results and Discussion}

Literature suggests that active principle of C. longa is insoluble in water. However, it is worth noting that bioactive components of natural colours do not occur in isolation in nature, but usually glycosylated (Oszmianski et al., 2004).Hence, glycosylation is suggested to be the principal factor accounting for aqueous solubility of active constituents of $C$. longa as instantaneous colouration of hot water appeares on addition of $C$. longa powder. Thus, water is used as one

\begin{tabular}{|c|c|c|c|c|c|c|}
\hline $\begin{array}{l}\text { Independent } \\
\text { variable }\end{array}$ & $\begin{array}{l}\text { Statistical } \\
\text { term }\end{array}$ & DF & SS & MS & $\begin{array}{l}\text { F-Ratio } \\
\text { calculated }\end{array}$ & $\begin{array}{l}\text { Tabulated } \\
5 \%\end{array}$ \\
\hline \multirow[t]{5}{*}{ Phenolic content } & First order & 3 & 0.00207953 & 0.0006931756 & 21.1198 & 5.41 \\
\hline & Second order & 6 & 0.00149 & 0.0002483 & 7.5933 & 4.95 \\
\hline & Lack of fit & 5 & 0.0002885 & 0.0000577 & 1.76 & 5.05 \\
\hline & Error & 5 & 0.0001635 & 0.0000327 & & \\
\hline & Total & 19 & & & & \\
\hline \multirow[t]{5}{*}{ Tinctorial index } & First order & 3 & 0.2295556 & $0.0765185^{\prime}$ & 30.125 & 5.41 \\
\hline & Second order & 6 & 0.097061 & 0.01617684 & 6.3688 & 4.95 \\
\hline & Lack of fit & 5 & 0.0401 & 0.00802 & 3.15748 & 5.05 \\
\hline & Error & 5 & 0.0127 & 0.00254 & & \\
\hline & Total & 19 & & & & \\
\hline \multirow[t]{5}{*}{ Relative total soluble solids } & First order & 3 & 228.872 & 76.291 & 55.8497 & 5.41 \\
\hline & Second order & 6 & 47.9911 & 7.998 & 5.857 & 4.95 \\
\hline & Lack of fit & 5 & 28.06 & 5.612 & 4.1083 & 5.05 \\
\hline & Error & 5 & 6.831 & 1.366 & & \\
\hline & Total & 19 & & & & \\
\hline
\end{tabular}
of the solvents in this study due to ready availability

Table 3. Regression coefficients for the quadratic model equation for extraction of crude constituent of $C$. longa

\begin{tabular}{llllllll}
\hline \hline $\begin{array}{l}\text { Sum of } \\
\text { products }\end{array}$ & Phenolic content & $\begin{array}{l}\text { Relative total } \\
\text { soluble solids }\end{array}$ & $\begin{array}{l}\text { Tinctometric } \\
\text { property }\end{array}$ & $\begin{array}{l}\text { Regression } \\
\text { coefficients }\end{array}$ & Phenolic content & $\begin{array}{l}\text { Relative total } \\
\text { soluble solid }\end{array}$ & $\begin{array}{l}\text { Tinctometric } \\
\text { property }\end{array}$ \\
\hline & & & & & & & \\
$0 \mathrm{y}$ & 0.473 & 335 & 5.46 & $\mathrm{~b} 0$ & 0.03549 & 18.1668 & 0.36412 \\
$\mathrm{y}$ & 0.1267 & 54.96 & 1.6023 & $\mathrm{~b} 1$ & 0.00928 & 4.02439 & 0.11732 \\
$2 \mathrm{y}$ & 0.053 & 8.77 & 0.4364 & $\mathrm{~b} 2$ & 0.00388 & 0.642 & 0.03195 \\
$3 \mathrm{y}$ & 0.0976 & -5.31 & 0.61414 & $\mathrm{~b} 3$ & 0.007150 & -0.389 & 0.04496 \\
$11 \mathrm{y}$ & 0.308 & 205.35 & 3.5988 & $\mathrm{~b} 11$ & -0.00237 & -1.63 & -0.01914 \\
$32 \mathrm{y}$ & 0.223 & 227.98 & 2.9484 & $\mathrm{~b} 22$ & -0.00766 & -0.215 & -0.05979 \\
$33 \mathrm{y}$ & 0.229 & 227.98 & 3.0332 & $\mathrm{~b} 33$ & -0.00731 & -0.125 & -0.05449 \\
$12 \mathrm{y}$ & -0.005 & 1.00 & 0.02 & $\mathrm{~b} 12$ & -0.00063 & 0.125 & 0.00250 \\
$13 \mathrm{y}$ & -0.001 & 7.00 & 0.2 & $\mathrm{~b} 13$ & 0.00013 & 0.875 & 0.02500 \\
$23 \mathrm{y}$ & -0.005 & -1.00 & -0.2 & $\mathrm{~b} 23$ & -0.00063 & -0.125 & -0.02500 \\
$\Sigma$ (iiy) & 0.760 & 661.31 & 9.5804 & & & & \\
\hline \hline
\end{tabular}

Table 4. Analysis of Variance (ANOVA) for the Predictive Model Equations

$\mathrm{DF}=$ Degree of Freedom; SS = Sum of Square; MS = Mega Square 
Table 5. Residual analysis of assessed parameters

\begin{tabular}{|c|c|c|c|c|c|c|c|c|c|}
\hline \multirow[b]{2}{*}{$\begin{array}{l}\text { Expt } \\
\text { run }\end{array}$} & \multicolumn{3}{|c|}{ Total Phenolic content } & \multicolumn{3}{|c|}{ Relative total soluble solids } & \multicolumn{3}{|c|}{ Tinctorial index } \\
\hline & Observed & Predicted & Residual & Observed & Predicted & Residual & Observed & Predicted & Residual \\
\hline 1 & 0.003 & -0.00355 & 0.00655 & 14 & 12.70441 & 1.29859 & 0.11 & 0.038926 & - \\
\hline 2 & 0.015 & 0.01653 & -0.00153 & 18.2 & 18.75319 & -0.55319 & 0.30 & 0.21858 & 0.08142 \\
\hline 3 & 0.006 & 0.00673 & -0.00073 & 16 & 13.9884 & 2.0116 & 0.18 & 0.147836 & 0.032164 \\
\hline 4 & 0.02 & 0.02429 & 0.00429 & 20 & 20.53719 & -0.53719 & 0.38 & 0.337489 & 0.042511 \\
\hline 5 & 0.017 & 0.01227 & 0.00473 & 11 & 10.42641 & 0.57359 & 0.15 & 0.128866 & 0.021134 \\
\hline 6 & 0.033 & 0.03183 & 0.00117 & 18 & 19.97519 & -1.97519 & 0.44 & 0.4085196 & 0.03148 \\
\hline 7 & 0.022 & 0.02003 & 0.00197 & 12 & 13.21041 & -1.21041 & 0.12 & 0.137745 & -0.017745 \\
\hline 8 & 0.031 & 0.03707 & -0.00607 & 20 & 21.25919 & -1.25919 & 0.42 & 0.427428 & -0.00743 \\
\hline 9 & 0.006 & 0.013179 & -0.007179 & 4 & 6.788136 & -2.788136 & 0.08 & 0.1126279 & -0.03263 \\
\hline 10 & 0.051 & 0.0444 & 0.0066 & 23 & 20.326184 & 2.673816 & 0.45 & 0.5073153 & -0.057315 \\
\hline 11 & 0.001 & 0.0073 & -0.0063 & 17 & 16.478936 & 0.521064 & 0.05 & 0.1412667 & -0.091267 \\
\hline 12 & 0.026 & 0.02035 & 0.00565 & 18 & 18.6386 & -0.6386 & 0.25 & 0.2487616 & 0.001238 \\
\hline 13 & 0.003 & 0.00279 & 0.00021 & 17 & 18.213078 & -1.213078 & 0.03 & 0.134363 & -0.104363 \\
\hline 14 & 0.026 & 0.02684 & -0.00084 & 18 & 16.90448 & 1.09552 & 0.30 & 0.285641 & 0.014359 \\
\hline 15 & 0.030 & 0.03549 & -0.00549 & 18 & 18.1668 & -0.1668 & 0.35 & 0.364125 & -0.01413 \\
\hline 16 & 0.039 & 0.03549 & 0.00351 & 19 & 18.1668 & 0.8332 & 0.38 & 0.364125 & 0.015875 \\
\hline 17 & 0.032 & 0.03549 & -0.00349 & 20 & 18.1668 & 1.8332 & 0.30 & 0.364125 & -0.064125 \\
\hline 18 & 0.03 & 0.03549 & -0.00549 & 18 & 18.1668 & -0.1668 & 0.34 & 0.364125 & -0.024125 \\
\hline 19 & 0.038 & 0.03549 & 0.00251 & 17 & 18.1668 & -1.1668 & 0.45 & 0.364125 & 0.085875 \\
\hline 20 & 0.044 & 0.03549 & 0.00851 & 17 & 18.1668 & -1.1668 & 0.38 & 0.364125 & 0.015875 \\
\hline
\end{tabular}

Residual $=$ Observed - Predicted

and relatively low cost. Basically three technological parameters namely; phenolic content, tinctorial index and relative total soluble solids were evaluated for the extraction of crude constituents of $C$. longa. The constraints (Table 1) explored in this study, exerted varied extraction effects as shown by the three responses (Table 2) evaluated therefore, subsequently modeled for prediction of constituent extraction outcome that is dictated by constituent's functionality.

The central composite orthogonal design to fit the polynomial model for the extraction of the three classes of crude constituents in C. longa was accomplished as elicited by Cochran and Cox (1957). The computed sums of products and regression coefficients to fit the model are shown in Table 3.

Total phenolic content. One of the most important groups of natural product with respect to therapeutic or biological value is phenolics. Therefore, total phenolic content of the extracted crude constituents in the C. longa solution can give insight to therapeutic potential of the designated rhizome. Thus the quadratic model takes the form:
$\mathrm{P}_{\mathrm{t}}=0.03549+0.00928 \mathrm{X}_{1}+0.00388 \mathrm{X}_{2}+0.00715 \mathrm{X}_{3}-$ $0.00237 \mathrm{X}_{1}^{2}-0.00766 \mathrm{X}_{2}^{2}-0.00731 \mathrm{X}_{3}^{2}-0.00063 \mathrm{X}_{1} \mathrm{X}_{2}-$ $0.00013 \mathrm{X}_{1} \mathrm{X}_{3}-0.00063 \mathrm{X}_{2} \mathrm{X}_{3}$

The predicted total phenolic content $\mathrm{pt}$ for each of the experimental run and their respective residual are shown in Table 4. Examination of the residuals suggests that the fitted model was reasonably adequate. The assertion was confirmed on model testing. Added to this, the analysis of variance to test the fitness of the model is presented in Table 5. The first and second order terms were significant as shown by the higher calculated F-ratio in comparison with the tabulated values. However, since the calculated F-ratio for the lack of fit was lower than the tabulated value, adequacy of the fitted model is affirmed. One of the flexibilities affordable by this model is that it can be adapted for extraction of crude constituent of interest in terms of dietary colourant or bioactive (therapeutic) dominate.

Tinctorial index $\left(\mathbf{T}_{\mathbf{P}}\right)$. Poor tinctorial index is the foremost drawback of colourant of natural origin. However, it is gratifying to note that, such negativity is not the case with 
shade intensity of $C$. longa. Colourimetric power (index) of $C$. longa is higher than available synthetic colourants of similar shade (Henry, 1996). Therefore, predictive model for tinctorial index of crude extract of colourant from C. longa deserves determination. Thus the quadratic model takes the form:

$\mathrm{T}_{\mathrm{I}}=0.36412498+0.1173268 \mathrm{X}_{1}+0.03195495 \mathrm{X}_{2}+$ $0.0449698 \mathrm{X}_{3}-0.019149 \mathrm{X}_{1}^{2}-0.059799 \mathrm{X}_{2}^{2}-0.054499 \mathrm{X}_{3}^{2}$ $+0.0025 \mathrm{X}_{1} \mathrm{X}_{2}+0.025 \mathrm{X}_{1} \mathrm{X}_{3}-0.025 \mathrm{X}_{2} \mathrm{X}_{3}$

The predicted tinctorial index $\left(\mathrm{T}_{\mathrm{I}}\right)$ for each of the experimental run and their residual are presented in Table 4 . Their residuals suggest that the fitted model is adequate. The claim on adequacy of the model fitness was verified by conducting analysis of variance test (Table 5). Since the first and second order terms were significant as revealed by higher calculated F-ratio in comparison with tabulated values and the calculated F-ratio for the lack of fit were lower than the tabulated value, attesting adequacy of the model.

Relative total soluble solids (RTSS). Relative total soluble solids reflect a composite of colourant of the crude constituents of $C$. longa. Its value is principally dictated by solvent composition (mixture) and bio chemical nature of the crude constituents (i.e. colourant and phenolic compounds). Nevertheless, the other variables influence RTSS of $C$. longa constituents in solution. The quadratic model takes the form:

$\mathrm{RTSS}=18.1668+4.02439 \mathrm{X}_{1}+0.642 \mathrm{X}_{2}-0.389 \mathrm{X}_{3}-$ $1.63 \mathrm{X}_{2}^{1}-0.215 \mathrm{X}_{2}{ }_{2}-0.215 \mathrm{X}_{3}{ }_{3}+0.125 \mathrm{X}_{1} \mathrm{X}_{2}+0.875 \mathrm{X}_{1} \mathrm{X}_{3}$ $-0.125 \mathrm{X}_{2} \mathrm{X}_{3}$

Using same assessment protocol reported for previous model parameters, the fitness of RTSS model was evaluated using analysis of variance (Table 4) and residual analysis (Table 5) and found adequate.

\section{Conclusion}

Extraction of crude constituents of Curcuma longa using three process variables yielded constituent that could essentially be dietary colourant and antimicrobial bases. The models developed were found adequate to extract crude constituent of interest with respect to colourant or antibiotics from the C. longa powder. In addition, the preliminarily separated crude constituents could serve as feedstock for further processing to yield product of high functionality. Bearing in mind that C. longa is partly plant food, its constituents can be used as additive in food preparations that are subjected to heat but not necessarily exposed to light. Such foods are: bread, cake, potatoes, mayonnaise, rice, macaroni and frankfurters. The findings of this study also offer possibility for reducing transportation and packaging cost as a result of miniature volume of the crude constituents in comparison to the large size (bulk) of the milled rhizome.

\section{References}

Adeniji, M.O. 2003. Herbal Treatment of Human Diseases. pp. 23-42, Oynx International (Nig) Ltd, Ibadan, Nigeria.

Cochran, W.G., Cox, G.M. 1957. Experimental Design, $2^{\text {nd }}$ edition, pp. 335-357, John Wiley and Sons, New York., USA.

Henry, B.S. 1996. G.A.F. Henry, J.O. Houghton, (eds.). Natural Food Colourants, $2^{\text {nd }}$ edition, pp. 40-79, Blackie Academic and Professional-an Imprint of Chapman and Hall, London, UK.

Misra, K., Narain, U., Kapoor, N. 2007. Bio-active conjugates of curcumin having ester, peptide, thiol and disulfide links. The Journals Scientific and Industrial Research, 66: 647-650.

Oszmianski, J., Bakowska, A., Piacente, S. 2004. Thermodynamic characteristics of copigmentation, reaction of acylated anthocyanin isolated from blue flowers of Scutellaria baicalensis Georgi with copigments. The journal of the Science of Food and Agriculture, 84: 1500-1506.

Rojsitthisak, P., Wichitnithad, W., Nimmannit, U., Wacharasindhu, S.L. 2011. Synthesis, characterization and biological evaluation succinate prodrugs of curcuminoids for colon cancer treatment. Molecules, 16: 1888-1900.

Taga, M.S., Miller, E.E., Pratt, D.E.1984. Chia seeds as a source of natural lipid antioxidants. Journal of The American Oil and Chemical Society, 61: 928-932.

Wrolstrad, R.E., Culbertson, J.D., Cornwell, C.J., Mattick, L.R. 1982. Detection of adulleration in blackberry juice concentrate and wines. Journal of Association of Official Analytical Chemists, 65: 1417-1423. 